\title{
A Comparative Analysis Between RIPASA and Alvarado Scoring Systems for the Diagnosis of Acute Appendicitis- A Nepalese Perspective
}

\author{
Suman Baral ${ }^{\mathrm{a}, \mathrm{e}}$ Neeraj Thapa ${ }^{\mathrm{b}, \mathrm{e}}$ Raj Kumar Chhetri ${ }^{\mathrm{c}, \mathrm{e}}$ Rupesh Sharma ${ }^{\mathrm{d}, \mathrm{e}}$
}

\begin{abstract}
:
Introduction: Various diagnostic criteria have been described for acute appendicitis. For decades the most commonly used one has been Alvarado score. RIPASA scoring system has also been developed for Asian population which has shown highest sensitivity and diagnostic accuracy. This study aimed to compare these two diagnostic criteria in Nepalese population attending a tertiary center. Methods: Patients with clinically suspected acute appendicitis were classified according to both Alvarado and RIPASA scoring systems before undergoing surgery. Histopathological examination was taken as the gold standard for diagnosis. Statistical analysis was done using McNemar's test as applicable. Results: Ninety nine $(90 \%)$ patients had histologically confirmed appendicitis. With the cut-off value greater than 7.5 for RIPASA score; sensitivity, specificity, positive predictive value, negative predictive value, diagnostic accuracy and negative appendectomy rates were $94.5 \%, 27.27 \%, 92.16 \%, 37.5 \%, 88.18 \%$ and $7.84 \%$ respectively. With the cut-off value greater than 7 for Alvarado score, sensitivity, specificity, positive predictive value, negative predictive value, diagnostic accuracy and negative appendectomy rates were $71.72 \%, 72.73 \%, 95.95 \%$, $22.22 \%, 71.82 \%$, and $4.05 \%$ respectively. $94.5 \%$ of patients were correctly stratified by RIPASA under higher probability group while only $71.8 \%$ were classified by Alvarado ( $\mathrm{p}$ value $=0.0001$ ). Conclusion: RIPASA scoring system showed high sensitivity and diagnostic accuracy in comparison to Alvarado scoring system. So, this method can be applied in Nepalese setting for the diagnosis of acute appendicitis.
\end{abstract}

Keywords: Acute Appendicitis, Alvarado Score, RIPASA

\section{INTRODUCTION:}

With lifetime prevalence of one in seven, acute appendicitis has been one of the most common surgical emergencies worldwide.[1] It is a clinical diagnosis involving clinical history, examination and some laboratory parameters along with radiological examinations whenever required. Of various scoring systems, the most commonly used one for the diagnosis has been Alvarado score for the last two decades. Recently RIPASA (Raja

\footnotetext{
Submitted: 04 October, 2018

Accepted: 12 December, 2018

Published: 31 December, 2018

a - Lecturer, Department of Surgery

b - Assistant Professor, Department of Surgery

c - Associate Professor and Head, Department of Surgery

d - Lecturer, Department of Radiodiagnosis

e - Lumbini Medical College and Teaching Hospital, Pravas, Palpa
}

Corresponding Author:

Suman Baral

e-mail: brylsuman.sur@gmail.com

ORCID: http://orcid.org/0000-0003-0906-138X
IsteriPengiranAnakSaleha Appendicitis) scoring system has also been employed for Asian population and this has shown the highest sensitivity and diagnostic accuracy in comparison to Alvarado score.[2] Age of the patient, gender and duration of symptoms have not been attributed by Alvarado system which definitely confound the diagnosis of acute appendicitis. RIPASA scoring system, however, incorporates these parameters in the clinical criteria as well. We prospectively compared these two diagnostic criteria in 110 patients with right iliac fossa (RIF) pain and clinically suspected appendicitis.

\section{METHODS:}

This was a prospective analytical study conducted at Department of Surgery, Lumbini

\footnotetext{
How to cite this article:

Baral S, Thapa N, Chhetri RK, Sharma R. A Comparative Analysis Between RIPASA and Alvarado Scoring Systems for the Diagnosis of Acute Appendicitis- A Nepalese Perspective. Journal of Lumbini Medical College. 2018;6(2):5 pages. DOI: 10.22502/jlmc.v6i2.264. Epub: 2018 Dec 31.
} 
Medical College and Teaching Hospital, Tansen, Nepal from June 2017 to May 2018. Ethical approval was taken from Institutional Review Committee (IRC-LMC 05-E/018). A total of 110 patients presenting with RIF pain and clinically suspected appendicitis were classified according to Alvarado and RIPASA scoring systems. The required laboratory investigations like Complete Blood Count (CBC), Renal Function Test (RFT), routine urine examinations were sent and reports retrieved as mentioned in table 1. Ultrasound (USG) examination was done in every patient by a radiologist and Contrast Enhanced Computed Tomography (CECT) abdomen whenever deemed necessary. The patients were then taken to operation theatre. A proforma was designed and filled up by the surgical residents which included all the variables required.

The gold standard for the diagnosis was positive histopathology findings. Statistical Package for Social Sciences $\left(\right.$ SPSS $\left.^{\mathrm{TM}}\right)$ software version 16 was used for statistical analysis. McNemar's test was applied wherever feasible. Cut-off values for the analysis were 7.5 and 7 for RIPASA and Alvarado scoring systems respectively. RIPASA Scoring system comprises 18 variables and all total score of 17.5. A cut-off value of 7.5 was used which demonstrates the high probability of acute appendicitis. Alvarado scoring system contains eight variables and a score of more than seven demonstrates high probability of acute appendicitis. $[3,4]$

The descriptive data were presented as mean ${ }_{ \pm} \mathrm{SD}$ and $\mathrm{p}$ value less than 0.05 was considered significant. Receiver operating curve (ROC) was formulated and area under the curve (AUC) was calculated.

\section{RESULT:}

A total of 110 patients who underwent surgery were included in the study. The demographics and clinical characteristics of the study population is shown in table 2 . The mean age $\pm \mathrm{SD}$ of the patients was $26.84 \pm 15.14$ years. Ninety percent of the specimens turned out to be appendicitis. Twenty six patients had perforated appendicitis. The mean post-operative hospital stay $\mathrm{SD}$ was $3.97 \pm 2.06$ days. Thirteen patients developed post-operative complications of which two patients underwent reexploration for post-operative intestinal obstruction.

Table 3 presents the distribution of 110 patients in four groups according to RIPASA and Alvarado scores with optimum cut-off values of 7.5 and 7 respectively. Seventy one $(71.72 \%)$ patients were correctly placed into higher probability group according to Alvarado score however this number increased to 94 (94.95\%) while applying RIPASA score for the clinical diagnosis of acute appendicitis $(p=0.0001)$. Twenty eight patients were missed by Alvarado score and was classified into false negative

Table 1. RIPASA Scoring System

\begin{tabular}{|c|c|c|c|}
\hline & & Score & Patient score \\
\hline \multirow{2}{*}{ Gender } & Male & 1 & \\
\hline & Female & 0.5 & \\
\hline \multirow{2}{*}{ Age } & $<40$ years & 1 & \\
\hline & $>40$ years & 0.5 & \\
\hline \multirow{4}{*}{ Symptoms } & RIF pain & 0.5 & \\
\hline & Pain migration to RIF & 0.5 & \\
\hline & Anorexia & 1.0 & \\
\hline & Nausea and vomiting & 1.0 & \\
\hline \multirow{2}{*}{ Duration of symptoms } & $<48$ hours & 1.0 & \\
\hline & $>48$ hours & 0.5 & \\
\hline \multirow{5}{*}{ Signs } & RIF Tenderness & 1.0 & \\
\hline & Guarding & 2.0 & \\
\hline & Rebound Tenderness & 1.0 & \\
\hline & Rovsing’s Sign & 2.0 & \\
\hline & Fever $>37<39{ }^{\circ} \mathrm{C}$ & 1.0 & \\
\hline \multirow{2}{*}{ Investigations } & Raised WBC & 1.0 & \\
\hline & Negative Urinalysis & 1.0 & \\
\hline \multicolumn{2}{|l|}{ Foreign nationality } & 1.0 & \\
\hline \multicolumn{2}{|l|}{ Total } & 17.5 & \\
\hline
\end{tabular}


Table 2. Demographic and clinical characteristics of the patients $(n=110)$

\begin{tabular}{|c|c|c|}
\hline Variables & & Frequency $(\%)$ \\
\hline \multirow{2}{*}{ Gender } & Male & $59(53.64 \%)$ \\
\hline & Female & $51(46.36 \%)$ \\
\hline Age in years, mean \pm SD & & $26.84 \pm 15.14$ \\
\hline \multirow{2}{*}{ USG findings } & Positive & $99(90 \%)$ \\
\hline & Negative & $11(10 \%)$ \\
\hline Positive histology for appendicitis & & $99(90 \%)$ \\
\hline Negative histology for appendicitis & & $11(10 \%)$ \\
\hline Post-operative hospital stay ( days), mean \pm SD & & $3.97 \pm 2.06$ \\
\hline Mean Total hospital stay ( days), mean \pm SD & & $4.62 \pm 2.05$ \\
\hline Perforated appendicitis & & $26(23.63 \%)$ \\
\hline
\end{tabular}

group while RIPASA classified only five patients in this group. Mean RIPASA score for true positive cases was $10.17 \pm 1.5$ while true negative cases was $3 \pm 0.0$. Mean RIPASA score for perforated appendicitis was $10.26 \pm 1.15$. Mean total hospital stay (days) was higher in true positive cases in comparison to true negatives $(4.11 \pm 2.12$ vs $3 \pm 0.001)$.

Table 4 summarizes different variables at optimal cut-off level of $>7.5$ for RIPASA score and $>7$ for Alvarado score. The sensitivity for RIPASA was $94.5 \%$ (95\% CI: 88.61\%-98.34\%) while it was
\% (95\% CI: 39.03\% - 93.98\%) respectively (Mc Nemar $\chi 2=39.32, \mathrm{df}=1, \mathrm{p}$ value 0.062 ). Diagnostic accuracies were $88.18 \%$ (95\% CI: 80.64\% - 93.55\%) and $71.82 \%$ (95\% CI:62.4\% - 79.98\%) respectively. However, negative appendectomy rate was higher in case of RIPASA scoring system.

\section{ROC Analysis and Optimum Cut-off value} The ROC curves for RIPASA and Alvarado score have been shown in figure 1 . This demonstrates the plot of sensitivity versus specificity for these two

Table 3. Patient distribution according to RIPASA and Alvarado scores

\begin{tabular}{lcccccccc}
\hline Parameters & \multicolumn{2}{c}{ True Positive } & \multicolumn{2}{c}{ False Positive } & \multicolumn{2}{c}{ True Negative } & \multicolumn{2}{c}{ False Negative } \\
& Ripasa $>7.5$ & Alvarado $>7$ & Ripasa $>7.5$ & Alvarado $>7$ & Ripasa $<7.5$ & Alvarado $<7$ & Ripasa $<7.5$ & Alvarado $<7$ \\
Sample Size & 94 & 71 & 8 & 3 & 3 & 8 & 5 & 28 \\
\hline M:F & $54: 40$ & $40: 31$ & $0: 8$ & $0: 3$ & $0: 3$ & $0: 8$ & $5: 0$ & $19: 9$ \\
$\begin{array}{l}\text { Mean Age } \pm \text { SD } \\
\text { (years) }\end{array}$ & $26.8 \pm 15.4$ & $28.06 \pm 16.4$ & $28.88 \pm 18.6$ & $44 \pm 1.73$ & $18.67 \pm 0.57$ & $19.38 \pm 1.68$ & $29.2 \pm 19.3$ & $24.04 \pm 12.8$ \\
\hline $\begin{array}{l}\text { Total Score } \pm \text { SD } \\
\text { Mean Hospital }\end{array}$ & $10.17 \pm 1.5$ & $8.31 \pm 1.05$ & $10.62 \pm 1.4$ & $8 \pm 0.001$ & $5 \pm 0.001$ & $5 \pm 0.926$ & $4.5 \pm 1.36$ & $4.83 \pm 1.4$ \\
Stay \pm SD (days) & $4.11 \pm 2.12$ & $4.1 \pm 2.3$ & $3.75 \pm 1.90$ & $6.0 \pm 0.001$ & $3 \pm 0.001$ & $2.62 \pm 0.51$ & $2.4 \pm 0.54$ & $3.8 \pm 1.3$ \\
\hline
\end{tabular}

$71.72 \%$ (95\% CI:61.78\% - 80.31\%) for Alvarado score which was statistically significant (Mc Nemar $\chi 2=34.08, \mathrm{df}=1, \mathrm{p}$ value 0.0001$)$. Similarly, the specificity for RIPASA and Alvarado scores were $27.27 \%$ (95\% CI: $6.07 \%-60.97 \%)$ and 72.73 diagnostic scoring systems. As evident by the figure, AUC for RIPASA score is 0.93 ( $p$ value $=0.0001$ ) which is higher than that of Alvarado scoring system which is 0.74 ( $p$ value $=0.011$ ). Coordinates of the curve demonstrate the cut off value of 7.75

Table 4. Comparison between RIPASA and Alvarado scoring systems.

\begin{tabular}{lccc}
\hline Variable & RIPASA $>$ 7.5 (95\% CI) & Alvarado $>$ 7 (95 \% CI) & p value \\
Sensitivity & $94.5 \%(88.61-98.34)$ & $71.72 \%(61.78-80.31)$ & $0.0001 *$ \\
Specificity & $27.27 \%(6.07-60.97)$ & $72.73 \%(39.03-93.98)$ & $0.062 *$ \\
Positive Predictive Value & $92.16 \%(89.08-94.42)$ & $95.95 \%(89.95-98.43)$ \\
Negative Predictive Value & $37.5 \%(14.19-68.52)$ & $22.22 \%(15.04-31.56)$ \\
Diagnostic Accuracy & $88.18 \%(80.64-93.55)$ & $71.82 \%(62.4-79.98)$ \\
Negative Appendectomy Rate & $7.84 \%$ & $4.05 \%$ & \\
*MC Nemar's Test & &
\end{tabular}




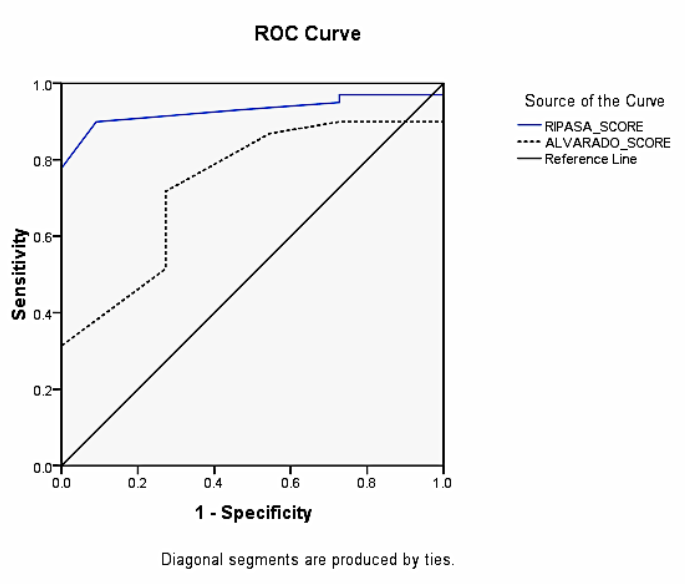

Figure 1. ROC plots for RIPASA and Alvarado scoring systems.

for RIPASA score which nearly corresponds to 7.5 which is the standard cut off value as given for the Asian population.

\section{DISCUSSION:}

Acute appendicitis is one of the most common surgical emergencies for all age groups with a life time prevalence of $7-8 \%$. $[1,5]$ The diagnosis of acute appendicitis is primarily based on clinicalfindings and laboratory examinations. Radiological examinations like USG and CECT have been used as adjuncts for the diagnosis and to look for the differentials. However use of these modalities have cost implications and requirement of experts for prompt diagnosis.[6]

Various scoring systems have been proposed for early diagnosis of acute appendicitis and Alvarado scoring system is the widely used.[7] However, owing to lack of high sensitivity and specificity which is as low as $59 \%$ and $23 \%$ respectively in Asian population, RIPASA scoring system has been developed which has been shown to achieve better sensitivity (88\%) and $\operatorname{specificity}(67 \%)$.[3]

So, we intended to apply RIPASA scoring system in the diagnosis of acute appendicitis at one of the tertiary centres in western Nepal and look for the sensitivity, specificity and diagnostic accuracy comparing with Alvarado scoring system.

A study by Singh A et al.[8] conducted on Indian population showed sensitivity of $95.89 \%$ and diagnostic accuracy of $90.5 \%$ for RIPASA which is comparable to our study (sensitivity $94.5 \%$ and diagnostic accuracy $88.18 \%$ ). This could be due to similar geography, shared lifestyles and exposure to similar risk factors for developing acute appendicitis. Another study by Singla A et al.[9] showed sensitivity of $95.6 \%$ and diagnostic accuracy of $81 \%$. Diagnostic accuracy for RIPASA was $80.50 \%$ in a study by Chong CF et al.[3] but study by Klabtawee $\mathrm{W}$ et al.[10] showed low accuracy of RIPASA in comparison to Alvarado.

However, specificity or true negative rate for RIPASA was quite low in our context $(27.27 \%)$ which did not corroborate to any other findings or studies. A study by Arroyo-Rangel C et al.[11]on Mexican population showed specificity as low as $71.4 \%$ while Karami MY et al.[12] showed as high as $91.67 \%$ in Iranian population. In Indian population, specificity for RIPASA was 80\%.[9] The reason behind low specificity in our study could be due to less number of cohorts who fall under this category.

Alvarado score showed sensitivity of 71.72 $\%$ which is comparable to a study by Jalil A et al.[4] which showed it to be $66 \%$. Similarly, true positiverate was $92.7 \%$ in a study by Xingye W et al.[13]in China.

Eleven patients who fell under true negative groups were operated either owing to USG / CECT findings despite clinical suspicion while some of these group of population underwent diagnostic laparoscopy and appendix was removed as benefit of doubt in absence of other findings.

There are some limitations in our study. The sample size might be small for validation of the scoring system. It definitely requires a larger cohort to carry out the comparative analysis of two scoring systems. A single institution based study might not include the aspects of the whole population of the country.

\section{CONCLUSION:}

RIPASA scoring system at a cut-off value of 7.5 is a better diagnostic tool for the diagnosis of acute appendicitis where other radiological diagnostic modalities are not feasible, especially in peripheral settings of the country. Higher sensitivity and diagnostic accuracy in comparison to Alvarado scoring system make RIPASA scoring system a better alternative for the diagnosis of acute appendicitis.

\section{Conflict of interest:}

The authors declare that no competing interests exist.

\section{Source of funds:}

No funds were available. 


\section{REFERENCES:}

1. Stephens PL, Mazzucco JJ. Comparison of ultrasound and the Alvarado score for the diagnosis of acute appendicitis. Connecticut Medicine. 1999 Mar;63(3):137-40. PMID: 10218289

2. Chong CF, Thien A, Mackie AJ, Tin AS, Tripathi S, Ahmad MA, Tan LT, Ang SH, Telisinghe PU. Comparison of RIPASA and Alvarado scores for the diagnosis of acute appendicitis. Singapore Medical Journal. 2011 May 1;52(5):340-5. PMID : 21633767 [Publisher Full Text]

3. Chong CF, Adi MI, Thien A, Suyoi A, Mackie AJ, Tin AS, Tripathi S, Jaman NH, Tan KK, Kok KY, Mathew VV. Development of the RIPASA score: a new appendicitis scoring system for the diagnosis of acute appendicitis. Singapore Medical Journal. 2010 Mar 1;51(3):220-5. PMID : 20428744 [Publisher Full Text]

4. Jalil A, Shah SA, Saaiq M, Zubair M, Riaz U, Habib Y. Alvarado scoring system in prediction of acute appendicitis. Journal of College of Physicians and Surgeons Pakistan. 2011 Dec 1;21(12):753-55. PMID: 22166697 DOI: $12.2011 /$ LCPSP.753755 [Publisher Full Text]

5. Al-Hashemy AM, Seleem MI. Appraisal of the modified Alvarado Score for acute appendicits in adults. Saudi Medical Journal. 2004;25(9):1229-31. PMID : 15448772 [Publisher Full Text]

6. Malik MU, Connelly TM, Awan F, Pretorius F, FiuzaCastineira C, El Faedy O, Balfe P. The RIPASA score is sensitive and specific for the diagnosis of acute appendicitis in a western population. International Journal of Colorectal Disease. 2017 Apr 1;32(4):491-7. PMID: 27981378 DOI: 10.1007/s00384-016-2713-4

7. Alvarado A. A practical score for the early diagnosis of acute appendicitis. Annals of Emergency Medicine. 1986 May 1;15(5):557-64. PMID: 3963537 DOI: 10.1016/S01960644(86)80993-3

8. Singh A, Parihar US, Kumawat G, Samota R, Choudhary R. To Determine Validation of RIPASA Score in Diagnosis of Suspected Acute Appendicitis and Histopathological Correlation with Applicability to Indian Population: a Single Institute Study. Indian Journal of Surgery. 2018 Apr 1;80(2):113-7. Epub 2018 Feb 2. PMID: 29915475 DOI: 10.1007/s12262-018-1731-6
9. Singla A, Singla S, Singh M, Singla D. A comparison between modified Alvarado score and RIPASA score in the diagnosis of acute appendicitis. Updates in Surgery. 2016 Dec 1;68(4):351-5. PMID: 27338243 DOI: $10.1007 /$ $\underline{\mathrm{s} 13304-016-0381-0}$

10. Klabtawee W, Saensak W, Khetsoongnern A, Piriyasupong T. Accuracy of RIPASA and modified RIPASA score comparing with Alvarado score for diagnosis of acute appendicitis and complication of acute appendicitis. Khon Kaen Medical Journal. 2011;35(1):38-47. [Publisher Full Text]

11. Arroyo-Rangel C, Limón IO, Vera ÁG, Guardiola PM, Sánchez-Valdivieso EA. Sensitivity, Specificity and Reliability of the RIPASA Score for Diagnosis of Acute Appendicitis in Relation to the Alvarado Score. Cirugía Española. 2018 Mar 1;96(3):149-54. PMID: 29486897 DOI: $10.1016 /$ j.ciresp.2017.11.013

12. Karami MY, Niakan H, Zadebagheri N, Mardani P, Shayan Z, Deilami I. Which One is Better? Comparison of the Acute Inflammatory Response, Raja Isteri Pengiran Anak Saleha Appendicitis and Alvarado Scoring Systems. Annals of Coloproctology. 2017 Dec 1;33(6):227-31. PMID: 29354605 DOI: 10.3393/ac.2017.33.6.227 [Publisher Full Text]

13. Xingye W, Yuqiang L, Rong W, Hongyu Z. Evaluation of Diagnostic Scores for Acute Appendicitis. Journal of the College of Physicians and Surgeons Pakistan. 2018 Feb 1;28(2):110-4. PMID: 29394968 DOI: 10.29271/ jcpsp.2018.02.110 